\title{
Metadata for recordings
}

The examples in this grammar come from a number of sources which are described below. Metadata is not given for individual recordings because the information is too extensive. Where recordings have been lodged with AIATSIS, The Language Archive or the Endangered Language Archive, the information about each recording is publicly available.

\section{HALE_K06 recordings}

This is a subset of the larger Ken Hale corpus which contains extensive and comprehensive elicitation of languages across northern and central Australia. In the case of Gurindji, it is a set of 120 pages of fieldnotes (a neatly written set of fieldnotes derived from a larger less legible set) and two hours of accompanying recordings made with Smiler Major at Wave Hill Station in 1959. They are lodged with AIATSIS as MS864(1) and HALE_K06-004553-004455. We are grateful to David Nash for copying the notes for us.

\section{MCCONVELL_P02 and_P04 recordings}

These recordings were made at Daguragu in May 1974 by Patrick McConvell with Johnny Kijngayarri, Nugget Jinpal, Blanche Bulngari, Tommy Ngaliwin and Jimmy Manngayarri. They constitute around 17.5 hours of elicitation, narratives, conversations and procedural texts. They were transcribed, glossed and translated by hand originally and have since been typed up and sound-linked in CLAN through a UQ Summer Research Program. The full audio recordings and handwritten transcripts are archived with AIATSIS. They are archived under MCCONVELL_P02 and MCCONVELL_P04, but we use the original tape numbers.

\section{MCNAIR recordings}

This set of 6.5 hours of recordings were made from 1977-1981 by Helen and Norm McNair through the Summer Institute of Linguistics (now AuSIL) at Kalkaringi. Most of the recordings were made with Dandy Danbayarri, Blanche Bulngari and Pincher Nyurrmiari, with some additional recordings made with Clancy Pangkarna, Horace Walman, Doris Butler and Lily Punayi. The recordings are mostly narratives. They were transcribed (typed), translated and glossed at the time. Meakins since had the subcorpus keyed in and sound linked in CLAN by UQ Summer Research scholars including Elizabeth Hall, Jackie van den Bos and Vivien Dunn. 


\section{EC recordings}

This set of 8.5 hours of recordings were made by Erika Charola from 1997-1999 through Diwurruwurru-jaru Aboriginal Corporation (Katherine Regional Aboriginal Language Centre) at Kalkaringi. Most of the recordings were made with Ronnie Wavehill Wirrpnga and Dandy Danbayarri, with additional recordings made with Ida Malyik Nampin, Violet Wadrill, Molly Tupngali Nawurla and Biddy Wavehill Yamawurr. Most of the recordings consist of Dreaming stories and oral history accounts of the Victoria River District region.

\section{FM recordings}

This is a set of 42.5 hours of audio and video recordings which were made by Felicity Meakins between 2007-2018 through a number of grants including a DoBeS and ELDP grant and three Australian Research Council fellowships. Most of the recordings were made with Violet Wadrill, Biddy Wavehill Yamawurr and Topsy Dodd. Additional recordings were made with Banjo Ryan, Kitty Mintawurr, Sarah Oscar, Ena Oscar, Theresa Yibwoin, Connie Ngarrmaya, Marie Japan and Ronnie Wavehill. The recordings were transcribed and translated in CLAN. They consist of procedural texts, for example bush medicine and food collection and preparation, example sentence elicitation for the dictionary and narratives about Dreamings and history. 